\title{
Spontaneous dissociation of a conjugated molecule on the Si(100) surface
}

Lin, Rong; Galili, Michael; Quaade, Ulrich; Brandbyge, Mads; Bjørnholm, Thomas; Esposti, A.D.; Biscarini, F.; Stokbro, Kurt

Published in:

Journal of Chemical Physics

Link to article, DOI:

$10.1063 / 1.1480857$

Publication date:

2002

Document Version

Publisher's PDF, also known as Version of record

Link back to DTU Orbit

Citation (APA):

Lin, R., Galili, M., Quaade, U., Brandbyge, M., Bjørnholm, T., Esposti, A. D., Biscarini, F., \& Stokbro, K. (2002). Spontaneous dissociation of a conjugated molecule on the Si(100) surface. Journal of Chemical Physics, 117(1), 321-330. https://doi.org/10.1063/1.1480857

\section{General rights}

Copyright and moral rights for the publications made accessible in the public portal are retained by the authors and/or other copyright owners and it is a condition of accessing publications that users recognise and abide by the legal requirements associated with these rights.

- Users may download and print one copy of any publication from the public portal for the purpose of private study or research.

- You may not further distribute the material or use it for any profit-making activity or commercial gain

- You may freely distribute the URL identifying the publication in the public portal 


\title{
Spontaneous dissociation of a conjugated molecule on the $\mathbf{S i ( 1 0 0 )}$ surface
}

\author{
R. Lin, ${ }^{\text {a) }}$ M. Galili, U. J. Quaade, and M. Brandbyge \\ Mikroelektronik Centret, Technical University of Denmark, Building 345 east, DK-2800 Lyngby, Denmark \\ T. Bjørnholm \\ Nano-Science center, Department of Chemistry, Universitetsparken 5, DK-2100 Copenhagen Ø, Denmark \\ A. Degli Esposti and F. Biscarini \\ CNR-Istituto di Spettroscopia Molecolare, Via P. Gobetti 101, I-40129 Bologna, Italy \\ K. Stokbro \\ Mikroelektronik Centret, Technical University of Denmark, Building 345 east, DK-2800 Lyngby, Denmark
}

(Received 11 September 2001; accepted 2 April 2002)

\begin{abstract}
The adsorption mechanism of $\alpha$-sexithiophene $(\alpha-6 \mathrm{~T})$ on the clean $\operatorname{Si}(100)-(2 \times 1)$ surface has been investigated using scanning tunneling microscopy (STM) and first principles electronic structure calculations. We find that at submonolayer coverage, the $\alpha-6 \mathrm{~T}$ molecules are not stable and dissociate into monomers. We observe two different configurations of the monomers and have discussed the corresponding adsorption geometries based on theoretical calculations. The calculations elucidate how the fragments are absorbed on the surface, giving rise to the observed STM images. With increasing coverage, the STM images show the existence of complete $\alpha-6$ T molecules. In addition, results of the adsorption behavior of $\alpha-6 \mathrm{~T}$ molecules on the H-passivated $\operatorname{Si}(100)-(2 \times 1)$ surface are reported. On this surface the molecules are highly mobile at room temperature due to the weak molecule-substrate interaction. The STM results also indicate that they can easily be anchored at the defect sites. (C) 2002 American Institute of Physics.
\end{abstract}

[DOI: $10.1063 / 1.1480857]$

\section{INTRODUCTION}

In recent years studies of organic molecular adsorption on silicon surfaces have been largely stimulated by the scientific interest in organic modifications of silicon surfaces. ${ }^{1-3}$ By tapping into the vast resources of organic molecules, a wide variety of functionalities can be designed and incorporated with the existing silicon-based technology for new and improved semiconductor devices, e.g., molecular electronics, chemical sensors and "DNA chips." Prior to realization of hybrid organic molecule-silicon devices, a detailed understanding of adsorption behavior of various organic molecules on silicon surfaces becomes essential for controllably incorporating the organic functionalities with the silicon microelectronics technology. ${ }^{4}$

In the area of organic molecular adsorption on silicon, a lot of work has been focused on alkenes. ${ }^{4}$ Among the alkenes ethylene was the first molecule for which the adsorption structure on the $\operatorname{Si}(100)-(2 \times 1)$ surface was well established by experimental methods such as scanning tunneling microscope $(\mathrm{STM})^{5,6}$ and traditional surface science techniques ${ }^{7-10}$ as well as by theoretical simulations. ${ }^{11,12}$ It has been demonstrated that ethylene reacts with the silicon surface via the interaction between the $\mathrm{C}-\mathrm{C}$ double bond and silicon dimers, producing two $\mathrm{Si}-\mathrm{C}$ bonds (the so-called di- $\sigma$ bonding). Other alkenes are found to react in a similar fashion with the $\mathrm{Si}(100)$ surface, ${ }^{13-17}$ i.e., they bind to the surface also via the

\footnotetext{
${ }^{\text {a) }}$ Author to whom correspondence should be addressed. Electronic mail: rl@mic.dtu.dk
}

di- $\sigma$ bonding configuration. Besides simple alkenes, conjugated dienes such as 1,3-butadiene and 1,3-cyclohexadiene have been investigated. ${ }^{18-20}$ It is found that these conjugated dienes can react with $\mathrm{Si}-\mathrm{Si}$ dimers not only via one of the two $\mathrm{C}-\mathrm{C}$ double bonds, but also through both $\mathrm{C}-\mathrm{C}$ double bonds, resulting in multiple bonding structures on the surface. The reaction between a $\mathrm{Si}-\mathrm{Si}$ dimer and two $\mathrm{C}-\mathrm{C}$ double bonds is referred as the Diels-Alder reaction. The interesting aspect of this reaction is that it produces a six membered ring containing a residual $\mathrm{C}-\mathrm{C}$ double bond which may prove useful in further controlled chemical reactions at the interface. Furthermore, interaction between aromatic compounds, e.g., benzene, ${ }^{21-25}$ toluene $^{26}$ and thiophene, ${ }^{27}$ and the $\mathrm{Si}(100)$ surface has also been investigated. All these molecules show multiple bonding geometries on the surface. For instance, room-temperature STM images $^{22,25}$ clearly illustrate that three different images of the benzene molecule can be observed on the $\mathrm{Si}(100)-(2 \times 1)$ surface and these images correspond to three different adsorption geometries.

In our experiment, we focus on a large rodlike conjugated molecule, $\alpha$-sexithiophene $(\alpha-6 \mathrm{~T})$, which is a prototype molecule for devices such as field effect transistors (FETs), ${ }^{28-31}$ light emitting diodes (LEDs) ${ }^{32,33}$ and transistors (LETs) ${ }^{34}$ Besides the technological aspect of this molecule, the other reason for studying this molecule is that growth of oligothiophene thin films onto dielectric (oxidized silicon, ${ }^{35}$ mica $^{36-38}$ ), semimetal (HOPG) $)^{39}$ and metal surfaces ( $\mathrm{Au}, \mathrm{Ag}$, $\mathrm{Al})^{40-43}$ has been thoroughly studied. In comparison, the growth of large conjugated oligothiophene molecules onto 


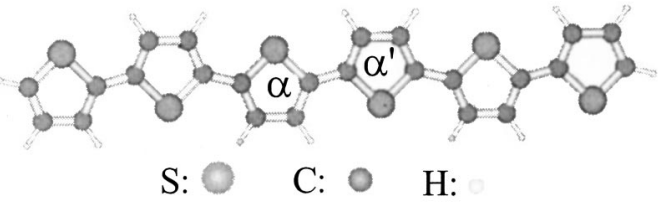

FIG. 1. Molecular structure of $\alpha$-sexithiophene. The $\alpha$ and $\alpha^{\prime}$ mark the C atoms adjacent to the sulfur atoms.

clean semiconductor surfaces is relatively unexplored. In order to gain the control needed to form highly perfect thin films, it is of considerable importance to study the adsorption behavior of $\alpha-6 \mathrm{~T}$ on silicon surfaces. In this work, by combining STM experiments with the first principles studies we elucidate the reactive processes occurring upon adsorption of $\alpha$-6T onto the clean $\mathrm{Si}(100)-(2 \times 1)$ surface and compare with the adsorption process of $\alpha-6 \mathrm{~T}$ on the corresponding $\mathrm{H}$-passivated Si surface. The difference of the two Si surfaces lies in the chemical reactivity. Due to the existence of dangling bonds on the clean $\mathrm{Si}$ surface, this surface is more reactive than the $\mathrm{H}$-passivated surface where the dangling bonds are passivated by hydrogen atoms. In this study we will show that the high reactivity of the $\mathrm{Si}(100)$ surface leads to fragmentation of the $\alpha$-6T molecules upon adsorption while the molecules adsorb intactly on the H-passivated surface.

\section{EXPERIMENT}

The experiments were performed in an ultrahigh vacuum (UHV) chamber pumped by an ion pump and a sublimation pump. The base pressures can be kept below 1 $\times 10^{-10}$ Torr. A load lock system enables efficient transfer of samples and tips without disrupting the vacuum system. The main chamber is equipped with a commercial STM (Danish Micro Engineering A/S). The molecular deposition system is attached to the load lock and can therefore be pumped separately without disrupting the vacuum condition in the main champer. The deposition system consists of an evaporator, a shutter and a quartz crystal microbalance.

In the experiment commercial n-type $\mathrm{Si}(100)$ wafers with a resistivity of $1 \Omega \cdot \mathrm{cm}$ were used as substrates. The clean reconstructed $\mathrm{Si}(100)-(2 \times 1)$ surfaces were prepared inside the main chamber by flashing the sample up to $1473 \mathrm{~K}$ for a few seconds, and cooling the sample with a rate around $5 \mathrm{~K} / \mathrm{s}$ to room temperature. Prior to the flashing process the sample was degassed at $923 \mathrm{~K}$ for at least $12 \mathrm{~h}$. The base pressure during annealing was kept below $5 \times 10^{-10}$ Torr. The $2 \times 1$ reconstruction was verified by STM imaging. H-passivated $\mathrm{Si}(100)-(2 \times 1)$ surfaces were prepared by exposing clean $\mathrm{Si}(100)-(2 \times 1)$ surfaces to atomic hydrogen for 6 min with a chamber pressure of about $1 \times 10^{-6}$ Torr. During exposure the temperature of the silicon substrate was kept at $623 \pm 25 \mathrm{~K}$. A hot W filament was used for cracking the hydrogen gas.

The molecular structure of $\alpha$-sexithiophene (hereafter referred to as 6T) is depicted in Fig. 1. The mass spectroscopy measurement showed that except for the initial ionization of the $6 \mathrm{~T}$ molecules to $6 \mathrm{~T}^{+1}$ ions, no fragmentation was observed during sublimation. The melting point of $6 \mathrm{~T}$ is 576 $\pm 1 \mathrm{~K}$. Prior to the deposition, the molecules were degassed, and then evaporated on the sample surfaces via sublimation at a rate of $0.01-0.02 \AA / s$, which was monitored with a quartz crystal microbalance. The deposition time for the clean silicon surfaces ranged from 5 to $10 \mathrm{~s}$, while for the $\mathrm{H}$-passivated surface the time ranged from 30 to $60 \mathrm{~s}$ with a rate of $0.05-0.10 \AA / \mathrm{s}$. The coverage of the molecules was estimated from the STM images. Tungsten tips were prepared by electrochemical etching and were subsequently cleaned inside the chamber by $\mathrm{Ar}^{+}$ion bombardment. Constant current STM images were acquired with the sample bias ranging from -2.0 to $-2.5 \mathrm{~V}$.
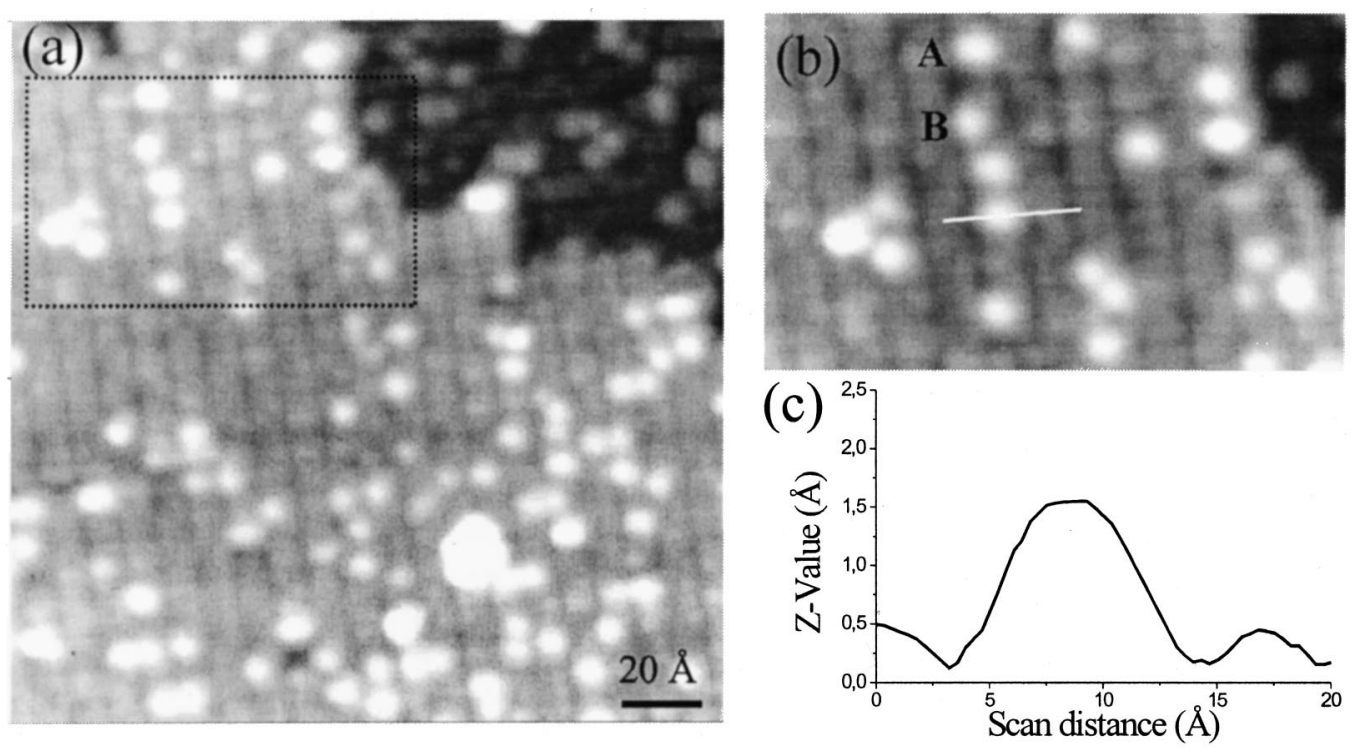

FIG. 2. (a) An STM image of the $\mathrm{Si}(100)-(2 \times 1)$ surface after deposition of a submonolayer coverage of $6 \mathrm{~T}$ molecules $\left(I_{\text {tunnel }}=0.15 \mathrm{nA} ; V_{\text {sample }}=-2.5 \mathrm{~V}\right)$. (b) The magnified STM image of the highlighted part of (a). A and B mark the two different types of the ball-like protrusions. (c) The cross-section profile along the line in (b). 

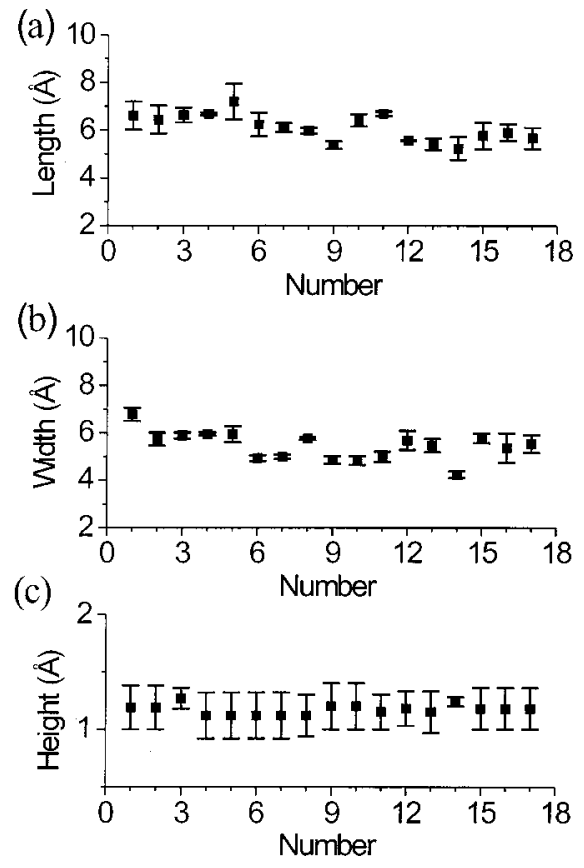

FIG. 3. The dimensions of 17 isolated bright spots in Fig. 2 measured in three directions: length, width and height based on the cross-section profile analysis.

\section{RESULTS}

\section{A. Submonolayer coverage}

Figure 2 shows an STM image of the $\mathrm{Si}(100)-(2 \times 1)$ surface after deposition of $6 \mathrm{~T}$ molecules. The underlying $\mathrm{Si}(100)$ surface structure is visible in the image. On the $\mathrm{Si}(100)$ surface, adjacent silicon atoms on the topmost layer pair into dimers via a strong $\sigma$-bond and a weak $\pi$-bond. In the filled state image, Si dimers are imaged as bean-shaped protrusions arranged in rows with an interrow distance of $7.68 \AA$ A. At the step edge, with an atomic step height of 1.36 $\AA$ the dimer rows on the upper terrace are orthogonal to those on the lower terrace due to the directional covalent bond. Beside the dimer row structure, the image also clearly reveals many bright ball-like protrusions on the surface. They are distributed across the surface as either isolated spots or small clusters. There is no indication of preferential adsorption towards the step edges. To identify these bright ball-like protrusions on the surface, a cross-section profile analysis was performed for 17 isolated bright spots. The size is given by the value of the full width at half-maximum (FWHM) of cross-section line profile. A line profile for one selected ball-like protrusion in the magnified STM image [Fig. 2(b)] is displayed in Fig. 2(c). The sizes of the spots measured in three directions are depicted in Fig. 3. The sizes measured in two directions, perpendicular to and along the dimer rows, are referred as the length and the width, respectively. The third one corresponds to the height of the protrusions. The average value of length, width and height of these spots are found to be $6.5 \pm 0.6 \AA, 5.8 \pm 0.6 \AA$, and 1.2 $\pm 0.2 \AA$, respectively. This result was further confirmed by many other STM images recorded for different samples and tips. Although the values for the length and the width are scattered, they are significantly smaller than the length of a

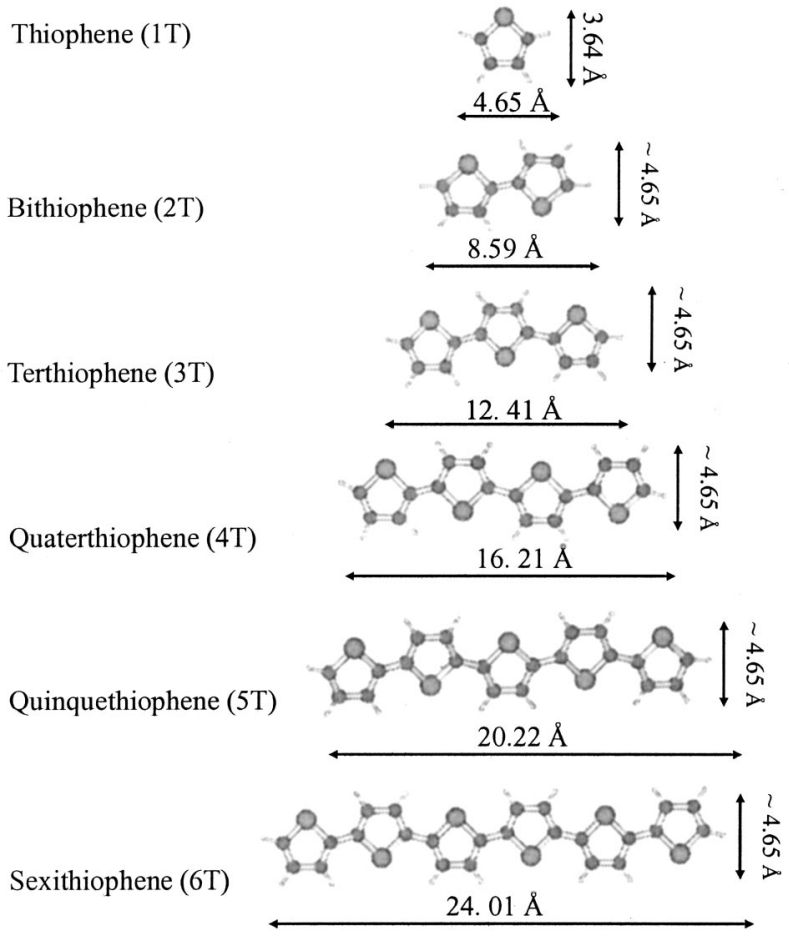

FIG. 4. Molecular structures and dimensions of thiophene and its oligomers.

6T molecule, which is about $24 \AA$. Thus, no 6T molecules are observed after deposition of $6 \mathrm{~T}$ molecules on the $\mathrm{Si}(100)-(2 \times 1)$ surface at low coverage.

Figure 4 displays the molecular structure of thiophene and its oligomers $(2 \leqslant n \leqslant 6)$ obtained by optimizing the molecular structure using the semi-empirical PM3 method. ${ }^{44}$ And we report the lengths as measured by the distance between the two terminal $\mathrm{H}$ atoms bound to the $\mathrm{C}_{\alpha}$ atoms at the end rings. By comparing the size of the protrusions obtained in Fig. 2 with that of oligothiophenes, we find that these bright protrusions have sizes most close to $1 \mathrm{~T}$. The average ratio of the length to the width of these spots is found to be 1.1 , in good agreement with a $1 \mathrm{~T}$ molecule whose ratio is 1.3. It is also well known that the size of adsorbates estimated by the cross-section profiles normally does not reflect the true geometric size of the adsorbates due to the complex interplay between the STM tip and the electronic structure of the substrate and adsorbate. Thus, the discrepancy between the measured and expected size of $1 \mathrm{~T}$ could be caused by this kind of the tip-sample convolution. Our observation suggests that upon adsorption on the $\mathrm{Si}(100)-(2 \times 1)$ surface at submonolayer coverage, due to the reactive $\mathrm{Si}$ dangling bonds, 6T molecules are not stable and dissociate into $1 \mathrm{~T}$ fragments by breaking the $\mathrm{C}_{\alpha}-\mathrm{C}_{\alpha}^{\prime}$ bonds.

The position of these protrusions with respect to the underlying Si dimer rows was further investigated by a careful inspection of the images. It was found that there are two different types of ball-like protrusions, marked by A and B in Fig. 2(b). For type A the ball-like protrusion is located exactly in the middle of the silicon dimer row, so referring to the dimer row it is symmetric. For type B, the bright spot is closer to one of the silicon dimer atoms, and therefore they are asymmetric with respect to the dimer row. Since many of 

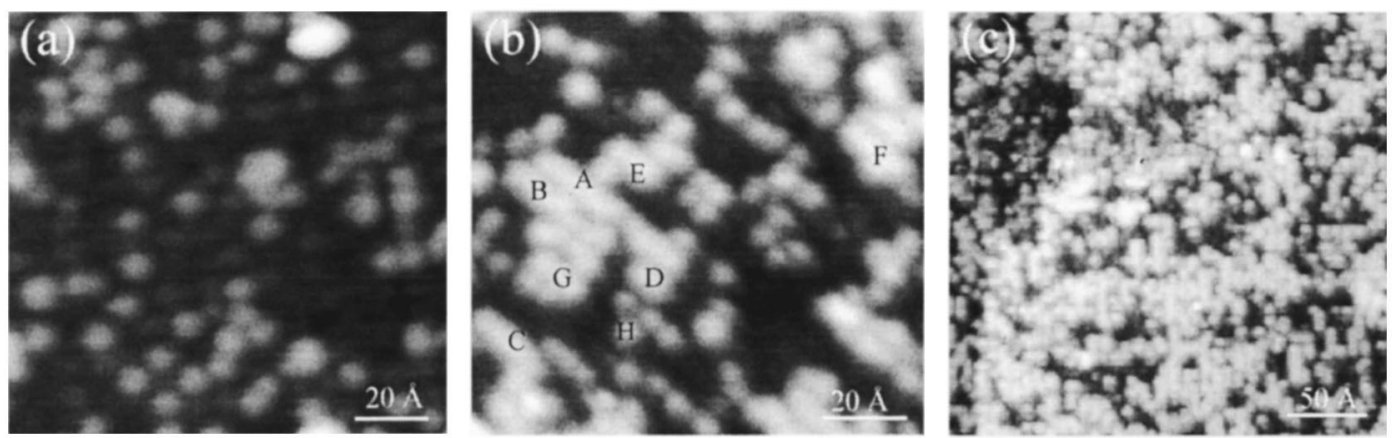

FIG. 5. A sequence of STM images [from (a) to (c)] of the clean silicon surface upon increasing doses of 6T. In (b) seven bar-shaped protrusions of different lengths are labeled and the measured lengths are plotted in Fig. 6.

these bright spots are agglomerated in clusters, it is difficult to make a reliable estimation of the relative percentage of types A and B.

\section{B. High coverage}

Figure 5 shows a sequence of STM images of the clean Si surface upon increasing the dose of 6T. With increasing coverage, the concentration of bright ball-like protrusions is also increasing, as shown in Fig. 5(a). Most protrusions are in clusters and located on top of the dimer rows. Further deposition leads to new features, bar-shaped (BS) protrusions, appearing in the image [Fig. 5(b)]. It is found that all the BS protrusions with different lengths have the long axes oriented in the same direction as the underlying dimer rows. Moreover, the BS protrusions appear brighter than most of the ball-like protrusions. The height profiles reveal that BS protrusions are about $0.4 \AA$ higher than the slightly dim balllike spots. This gives us an indication that these BS protrusions are not directly lying on top of the silicon dimers. Instead they may locate on top of the ball-like protrusions. By further increasing the coverage, BS protrusions with different sizes become dominant on the surface, as shown in Fig. 5(c). We do not observe any ordering of the BS protrusions.

Seven different BS protrusions, labeled in Fig. 5(b), were selected, and the measured lengths of these seven protrusions are plotted in Fig. 6. Due to the tip-sample convolution, we expect that the apparent size of these BS protrusions will be larger than their real size. Therefore, we also

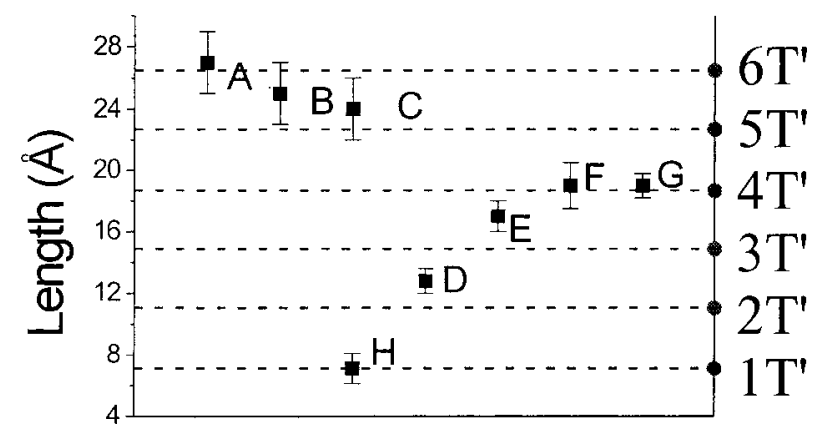

FIG. 6. The lengths of the seven bar-shaped protrusions labeled in Fig. 5. The molecular lengths of thiophene and oligomers up to $6 \mathrm{~T}$, including the tip broadening effect, are plotted as the dashed lines. estimated the size broadening by calculating the size difference between the average size of the ball-like protrusions in the image and the size of 1T. The average length and width of the ball-like protrusion are found to be 7.1 and $6.1 \AA$, respectively, which are in accordance with the values obtained for the protrusions in Fig. 2. Thus the size broadening in this image is estimated to be about $2.5 \AA$. In order to get a quick impression what these BS protrusions correspond to, in the same figure the "lengths" of thiophene and oligomers up to $6 \mathrm{~T}$, including the tip broadening effect, are plotted as the dashed lines for the eye guiding. It is seen that the sizes of the different BS protrusions are close to the sizes of oligothiophene for $2 \leqslant n \leqslant 6$. We admit that there are some uncertainties in the method used to estimate the tip broadening effect. However, we are sure that longer oligomeric fragments (ring number $>1$ ) start to appear on the surface after

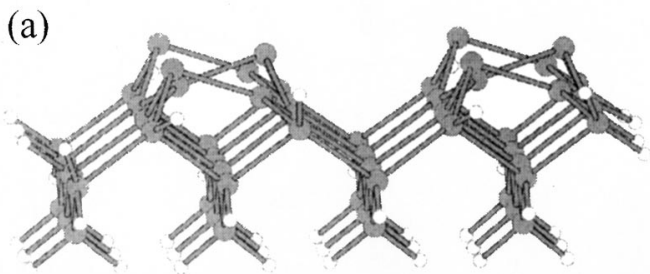

(b)

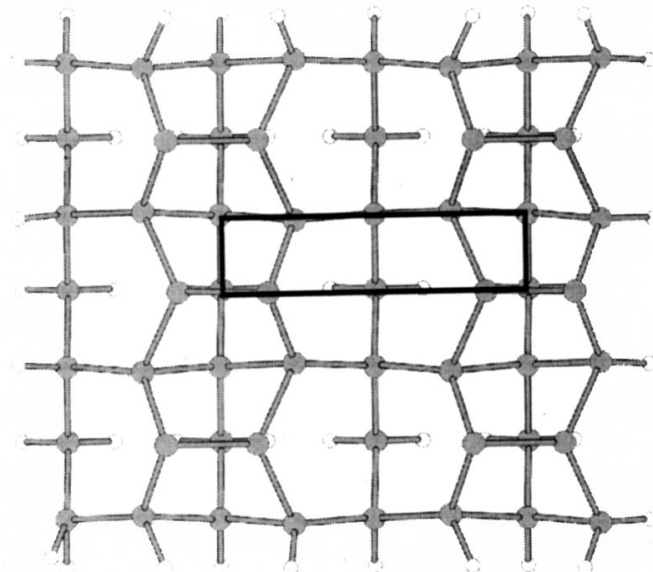

FIG. 7. Side view (a) and top view (b) of the cluster used to describe the $\mathrm{Si}(100)$ surface. There are a total of $56 \mathrm{Si}$ and $48 \mathrm{H}$ atoms. The solid rectangle in (b) shows the irreducible part of the surface. 
(a)

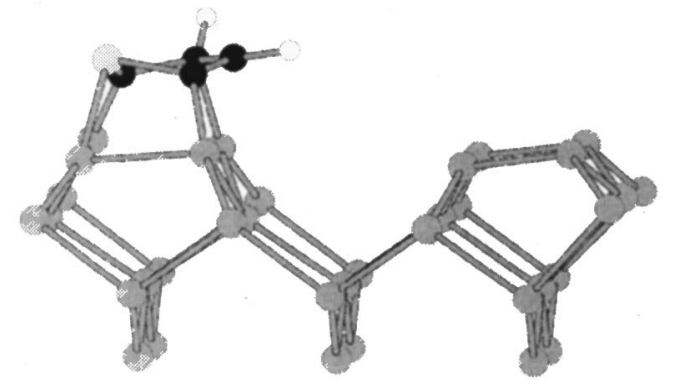

(b)

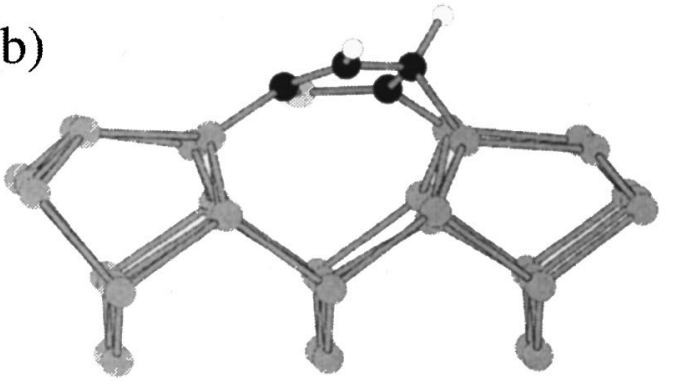

(c)

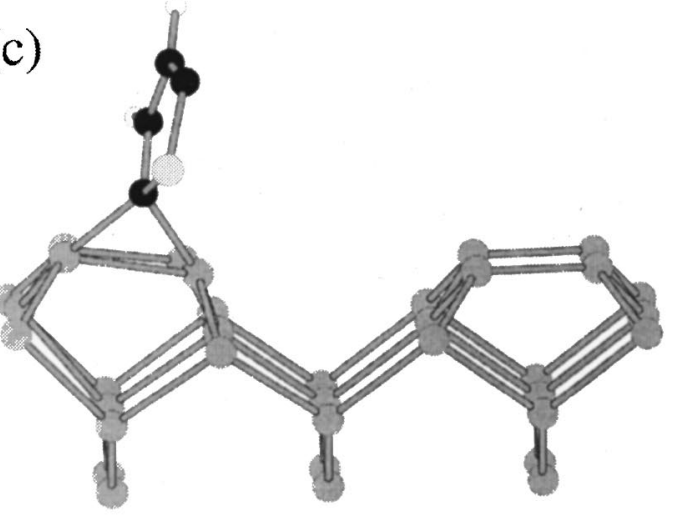

FIG. 8. The three different classes of $\mathrm{SC}_{4} \mathrm{H}_{2}$ adsorption geometries obtained with the AM1 method.

the dangling bonds are passivated with the monomeric fragments.

\section{FIRST PRINCIPLES MODELING}

Though the experimental data indicate that, due to strong interaction with the dangling bonds, 6T breaks into monomers at submonolayer coverage, they are not able to give details on the position of the underlying atoms. An accurate modeling of these fragments on the surface, therefore, helps to elucidate where they are preferentially absorbed on the surface and the main interactions among the atoms, which give rise to the observed STM images. From the molecular structure of $6 \mathrm{~T}$, we see that there are two different monomers upon $\mathrm{C}_{\alpha}-\mathrm{C}_{\alpha}^{\prime}$ bond breaking. The four middle monomers $\left(\mathrm{SC}_{4} \mathrm{H}_{2}\right)$ will be missing two $\mathrm{H}$ atoms, while the two outermost monomers $\left(\mathrm{SC}_{4} \mathrm{H}_{3}\right)$ will be missing only one $\mathrm{H}$ atom, relative to a thiophene molecule (1T). For this reason, we have investigated theoretically the adsorption geometry of the two fragments on the $\operatorname{Si}(100)$ surface with the
$\mathrm{DACAPO}^{45}$ electronic structure code. These calculations were based on density functional theory (DFT), and the generalized gradient approximation of Ref. 46 (PW91) was used for the exchange correlation energy. The wavefunctions of the valence electrons were expanded in a plane-wave basis set with an energy cutoff of 20 Rydberg, and the core electrons of $\mathrm{Si}, \mathrm{C}, \mathrm{H}$, and $\mathrm{S}$ were described by ultra-soft pseudo potentials. ${ }^{47}$ Within this approach the Si lattice constant was determined to be $a_{0}=5.46 \AA$. The $\operatorname{Si}(100)-\mathrm{p}(2 \times 2)$ surface was modeled by a $c(4 \times 4)$ slab with four layers, thus a total of $32 \mathrm{Si}$ atoms. The last two layers were fixed in bulk positions and dangling bonds on the lower surface were passivated with $\mathrm{H}$ atoms. A Gaussian broadening of $0.1 \mathrm{eV}$ and a (221) Monkhorst-Pack mesh ${ }^{48}$ for the Brillouin zone sampling (two $k$-points in the irreducible zone) were used. The atomic positions of the $\mathrm{Si}$ atoms in the first two layers were relaxed until the forces on the atoms were smaller than 0.2 $\mathrm{eV} / \AA$.

A systematic search for $\mathrm{SC}_{4} \mathrm{H}_{2}$ adsorption positions is too computationally demanding using this approach, and instead the semi-empirical Austin model (AM1) ${ }^{49}$ was applied to locate all the potential adsorption positions. These calculations were performed with the GAUSSIAN 98 package, ${ }^{50}$ which can only describe cluster geometries. For this purpose we extracted a four-layer $(4 \times 3)$ silicon cluster from the slab coordinates, and passivated all nonsurface dangling bonds with $\mathrm{H}$ atoms (see Fig. 7). The solid rectangle in Fig. 7(b)

\section{$\mathrm{SC}_{4} \mathrm{H}_{2}-\mathrm{aI}$}

(a)

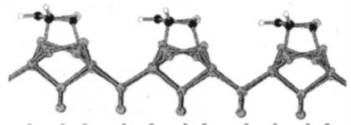

(b)

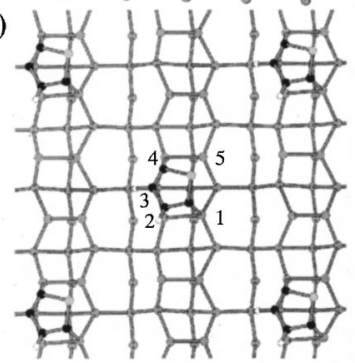

(c)

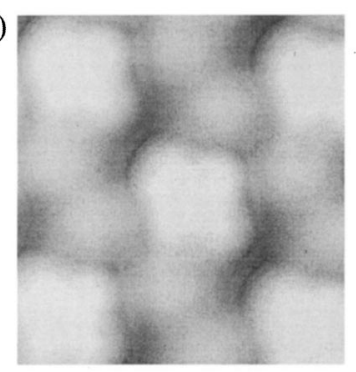

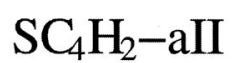

(d)

(e)

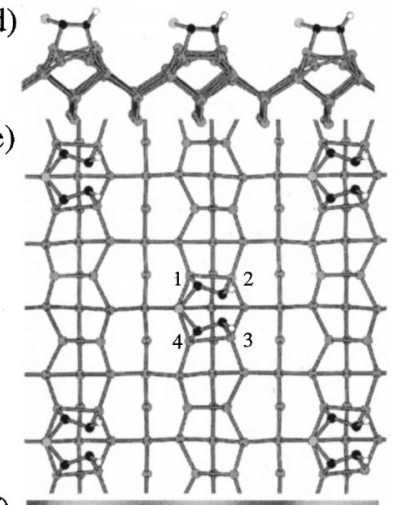

(f)

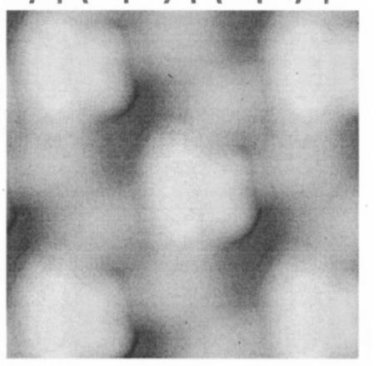

FIG. 9. The DFT optimized structure of the $\mathrm{SC}_{4} \mathrm{H}_{2}$ adsorption geometry with the lowest (aI) and the second lowest energy (aII). (a) and (d): Side views, (b) and (e): Top views. The numbering of the atoms defines atom labels in Table I. The numbers 1, 2, 3, and 4 are used to label the $\mathrm{C}$ atoms of $\mathrm{SC}_{4} \mathrm{H}_{2}$ and the $\mathrm{Si}$ atoms are labeled with the number of the $\mathrm{C}$ atom to which they bond. That means, in (a) the numbers 1, 2, 4 and 5 are also used to label the $\mathrm{Si}$ atoms and in (b) numbers 1, 2, 3, and 4 are used for labelling. (c) and (f): Tersoff-Hamann STM images corresponding to a sample bias of $-2.5 \mathrm{~V}$. 
TABLE I. Adsorption energy and structural parameters for the adsorption geometries of $\mathrm{SC}_{4} \mathrm{H}_{2}$ shown in Fig. 9. For comparison the adsorption energy and structural parameters of the most stable chemisorbed state of thiophene on $\mathrm{Si}(100)-(2 \times 1)$ (structure I), calculated by Jeong et al., are also listed. The adsorption energies are relative to an isolated singlet $\mathrm{SC}_{4} \mathrm{H}_{2}$ molecule and an isolated singlet silicon substrate. The triplet state of $\mathrm{SC}_{4} \mathrm{H}_{2}$ is $1.11 \mathrm{eV}$ more favorable than the singlet state within the AM1 approach. In the AM1 approach the molecule and the first two layers of silicon atoms are relaxed. In the DFT(1) approach the molecule and the first layer of silicon atoms are relaxed, while in the DFT(2) approach the first three layers of silicon atoms are relaxed. Bond lengths are in Ångström and angles in degrees.

\begin{tabular}{lccc}
\hline \multicolumn{1}{c}{ Energy } & $\mathrm{SC}_{4} \mathrm{H}_{2}$-aI & $\mathrm{SC}_{4} \mathrm{H}_{2}$-aII & Structure $\mathrm{I}^{\mathrm{a}}$ \\
\hline $\mathrm{AM} 1$ & $-8.73 \mathrm{eV}$ & $-7.91 \mathrm{eV}$ & -4.81 \\
$\mathrm{DFT}(1)$ & $-4.44 \mathrm{eV}$ & $-3.65 \mathrm{eV}$ & $\cdots$ \\
$\mathrm{DFT}(2)$ & $-4.88 \mathrm{eV}$ & $-4.28 \mathrm{eV}$ & $\cdots$ \\
& & & \\
Structural parameters & & & \\
$\mathrm{C}_{1}-\mathrm{C}_{2}$ & 1.524 & 1.513 & 1.521 \\
$\mathrm{C}_{2}-\mathrm{C}_{3}$ & 1.468 & 1.633 & 1.476 \\
$\mathrm{C}_{3}-\mathrm{C}_{4}$ & 1.368 & 1.517 & 1.347 \\
$\mathrm{~S}_{-} \mathrm{C}_{1}$ & 1.759 & 1.722 & 1.881 \\
$\mathrm{~S}_{1} \mathrm{C}_{4}$ & 1.855 & 1.717 & 1.784 \\
$\mathrm{Si}_{1}-\mathrm{C}_{1}$ & 1.897 & 1.931 & 1.908 \\
$\mathrm{Si}_{2}-\mathrm{C}_{2}$ & 2.058 & 2.006 & 1.933 \\
$\mathrm{Si}_{3}-\mathrm{C}_{3}$ & $\ldots$ & 1.993 & $\cdots$ \\
$\mathrm{Si}_{4}-\mathrm{C}_{4}$ & 1.925 & 1.936 & 2.539 \\
$\mathrm{Si}_{5}-\mathrm{S}$ & 2.539 & $\cdots$ & 2.347 \\
$\angle \mathrm{SC}_{1} \mathrm{C}_{2}$ & 106.5 & 109.5 & 106.3 \\
$\angle \mathrm{C}_{1} \mathrm{C}_{2} \mathrm{C}_{3}$ & 111.1 & 109.0 & 110.8 \\
$\angle \mathrm{C}_{2} \mathrm{C}_{3} \mathrm{C}_{4}$ & 117.3 & 109.3 & 117.1 \\
$\angle \mathrm{C}_{3} \mathrm{C}_{4} \mathrm{~S}$ & 105.9 & 109.3 & 112.5 \\
$\angle \mathrm{C}_{4} \mathrm{SC}_{1}$ & 94.4 & 99.7 & 92.5 \\
$\angle \mathrm{Si}_{1} \mathrm{C}_{1} \mathrm{~S}$ & 119.2 & 104.1 & 118.8 \\
$\angle \mathrm{Si}_{2} \mathrm{C}_{2} \mathrm{C}_{3}$ & 101.8 & 94.4 & 106.4 \\
$\angle \mathrm{Si}_{4} \mathrm{SC}_{1}$ & $\cdots$ & $\cdots$ & 115.1 \\
\hline \hline
\end{tabular}

Data from Reference 27.

represents the irreducible area of the surface, i.e., the smallest area that can represent the entire surface. If the center of the mass of the molecular fragment is positioned within this area, the results can be generalized to the entire surface by using the symmetry operations of the surface. In the case of $\mathrm{SC}_{4} \mathrm{H}_{2}$, the molecule was placed in eight different points along the long axis and three along the short axis. In each point the molecule was turned 360 degrees parallel to the surface in steps of 30 degrees. This gives a total of 288 different initial positions, and in each geometry all $\mathrm{SC}_{4} \mathrm{H}_{2}$ atoms were allowed to relax, while the $\mathrm{Si}$ atoms were kept in fixed positions. In order to facilitate rotations perpendicular to the surface, the starting geometry of $\mathrm{SC}_{4} \mathrm{H}_{2}$ was tilted a few degrees relative to the surface. The geometries with the lowest energy obtained from this search were used as input to a second set of calculations where also Si atoms in the first two layers were allowed to relax.

The relaxed geometries can be sorted into three different classes, and a representative for each class is shown in Fig. 8. In class (a) the $\mathrm{SC}_{4} \mathrm{H}_{2}$ molecule is positioned parallel to the surface within a dimer row. In class (b) the molecule is positioned between two rows of dimers, while in class (c) the molecule stands on the surface. The geometries in class (a) have AM1 energies that are more than $1 \mathrm{eV}$ lower than the geometries in the other two classes, and therefore in the following we will therefore only consider class (a) geometries.

\section{(a) Along the dimer row}

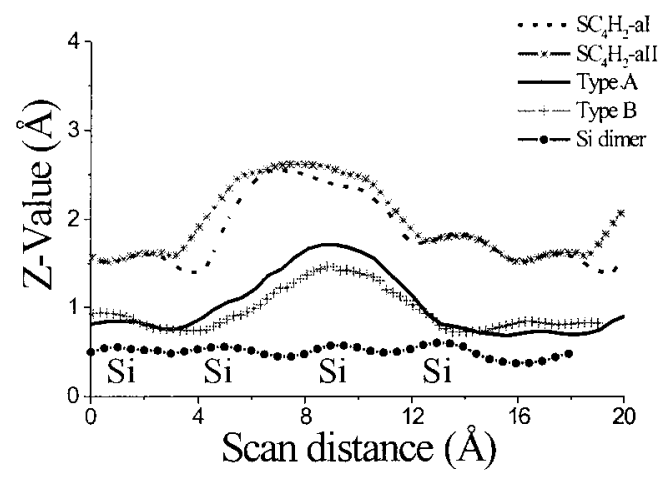

(b) Perpendicular to dimer rows

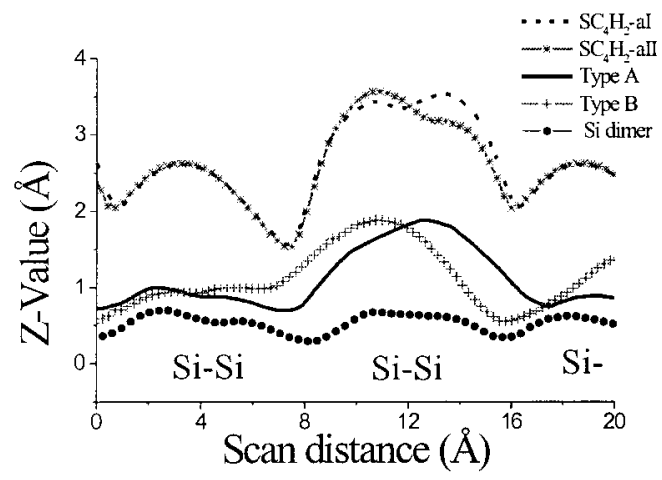

FIG. 10. Line profiles (upper) of the simulated STM image of $\mathrm{SC}_{4} \mathrm{H}_{2}$-aI and aII geometries together with line profiles (lower) of the experimental STM images for type A and type B along (a) and perpendicular to (b) the Si dimer row. The line profiles measured along and across silicon dimer rows are also plotted as references.

Within class (a) there are two local minima, illustrated in Figs. 9(a) and 9(d), which we denote geometry aI and aII. In Table I we show the adsorption energies of these two geometries as obtained by subtracting the total energy of the isolated molecule and the energy of the clean Si surface from the total energy of each geometry.

These two AM1 geometries were used as starting points for supercell DFT calculations. In Table I we show the calculated adsorption energies when the coordinates of the molecule and the first layer $\mathrm{Si}$ atoms were relaxed within the DFT approach (DFT1) and when coordinates of three layers of $\mathrm{Si}$ atoms were relaxed (DFT2). Compared to the AM1 results, the absolute value of the adsorption energy changes significantly, while relative differences are quite similar. Thus, in this case, the AM1 results seem to be quite accurate in predicting the most stable geometry. It is interesting to compare the obtained geometries with the adsorption geometries of thiophene on $\mathrm{Si}(100)$ which have been calculated with the AM1 method by Jeong, Lee and Kim. ${ }^{27}$ Comparison of the geometrical parameters shows that the most favorable adsorption geometry aI is very similar to the most favorable adsorption geometry of thiophene. In this geometry there is a double bond between $\mathrm{C}_{3}$ and $\mathrm{C}_{4}$ atoms. The main differences observed for $\mathrm{SC}_{4} \mathrm{H}_{2}$ are due to the larger reactivity of the $\mathrm{C}_{1}$ and $\mathrm{C}_{4}$ atoms of the diradical fragment, with respect to 
(a)

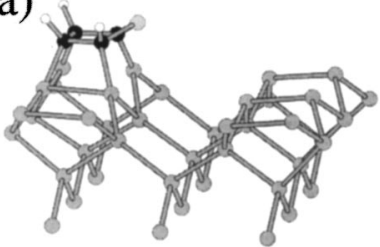

(c)

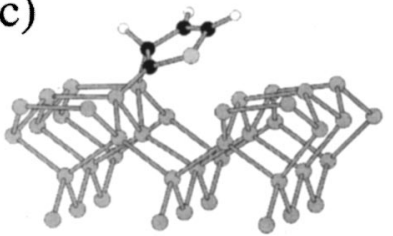

(b)

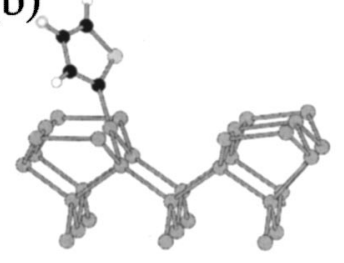

(d)

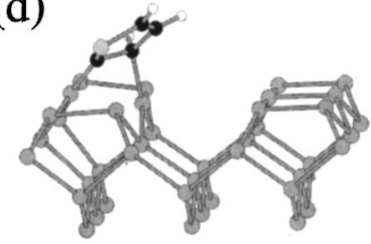

FIG. 11. The $\mathrm{SC}_{4} \mathrm{H}_{3}$ adsorption geometries using the $\mathrm{AM} 1$ method with the lowest energy $(-11.28 \mathrm{eV})$ (a) the second lowest energy $(-11.16 \mathrm{eV})(\mathrm{b})$ the third lowest energy $(-10.93 \mathrm{eV}$ ) (c) and the fourth lowest energy $(-10.60 \mathrm{eV})(\mathrm{d})$.

thiophene. In fact, though the $\mathrm{C}_{3}-\mathrm{C}_{4}$ bond preserves its character of a double bond, as the case of thiophene, the $\mathrm{C}_{4}$ atom has a larger interaction with the neighbor $\mathrm{Si}$ atom, indicated by the shorter $\mathrm{Si}_{4}-\mathrm{C}_{4}$ bond length. Besides, the $\mathrm{Si}_{1}-\mathrm{C}_{1}$ bond length is shortened, while that of $\mathrm{Si}_{2}-\mathrm{C}_{2}$ is lengthened, Moreover, as shown for the thiophene molecule, the $\mathrm{S}$ atom has a significant bonding interaction with a $\mathrm{Si}$ atom. The second stable chemisorbed state of thiophene found by Jeong, Lee and Kim is the one where the $\mathrm{C}_{1}$ atom is not bound to a $\mathrm{Si}$ atom. We do not find such a chemisorbed state for the $\mathrm{SC}_{4} \mathrm{H}_{2}$ molecule, presumably because in our case $\mathrm{C}_{1}$ and $\mathrm{C}_{4}$ atoms are the most reactive atoms. In the second stable chemisorbed state of thiophene, the $\mathrm{C}_{1}$ atom is not bound to a $\mathrm{Si}$ atom, while that calculated for the $\mathrm{SC}_{4} \mathrm{H}_{2}$ molecule shows larger interactions, especially among $\mathrm{Si}_{1}$ and $\mathrm{C}_{1}$ atoms as well as $\mathrm{Si}_{4}$ and $\mathrm{C}_{4}$ atoms. In this case, the diradical lies on the surface with $\mathrm{C}_{1}$ and $\mathrm{C}_{4}$ atoms, and $\mathrm{C}_{2}$ and $\mathrm{C}_{3}$ atoms almost equidistant from the closer $\mathrm{Si}$ atoms, while the $\mathrm{S}$ atom is not bound to a $\mathrm{Si}$ atom. In this chemisorbed state all four $\mathrm{C}$ atoms interact with the underlying silicon atoms, thus the $\mathrm{C}-\mathrm{C}$ bonds have a length of a single $\mathrm{C}-\mathrm{C}$ bond or of a broken bond $\left(\mathrm{C}_{2}-\mathrm{C}_{3}\right)$.

To compare the calculated adsorption geometry with the experimental data, we have made STM simulations using the Tersoff-Hamann model. ${ }^{51}$ Figures 9(c) and 9(f) show the cal-

TABLE II. Adsorption energy for the adsorption geometries of $\mathrm{SC}_{4} \mathrm{H}_{3}$ shown in Fig. 12. The adsorption energies are relative to an isolated doublet $\mathrm{SC}_{4} \mathrm{H}_{3}$ molecule and an isolated singlet silicon substrate. In the AM1 approach the molecule and the first two layers of silicon atoms are relaxed. In the DFT(1) approach the molecule and the first layer of silicon atoms are relaxed, while in the DFT(2) approach the first three layers of silicon atoms are relaxed. The DFT(3) calculation is a spin-polarized calculation with spin 1 for the DFT(2) geometry.

\begin{tabular}{lcc}
\hline \hline Energy & $\mathrm{SC}_{4} \mathrm{H}_{3}-\mathrm{a}(\mathrm{eV})$ & $\mathrm{SC}_{4} \mathrm{H}_{3}-\mathrm{b}(\mathrm{eV})$ \\
\hline $\mathrm{AM} 1$ & -11.28 & -11.16 \\
$\mathrm{DFT}(1)$ & -3.08 & -4.07 \\
$\mathrm{DFT}(2)$ & -3.70 & -4.49 \\
$\mathrm{DFT}(3)$ & -3.70 & -4.49 \\
\hline
\end{tabular}
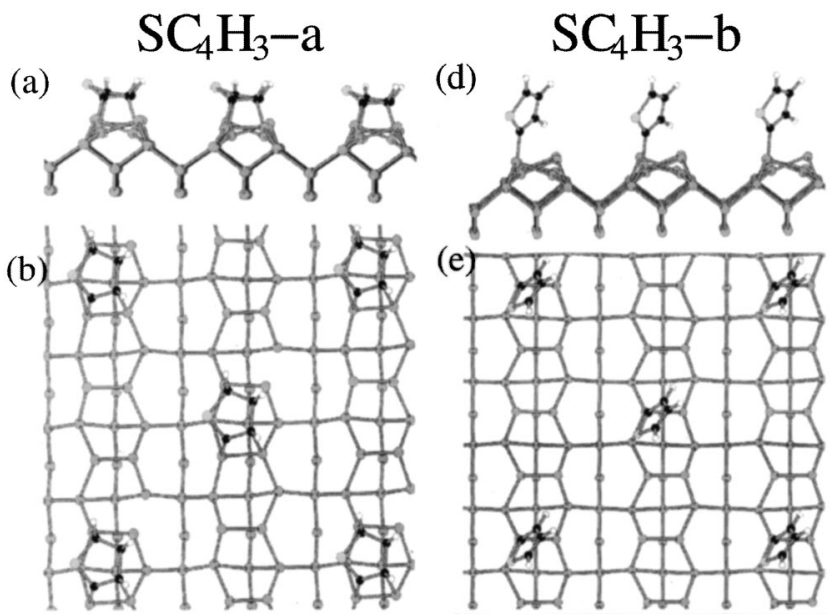

(c)
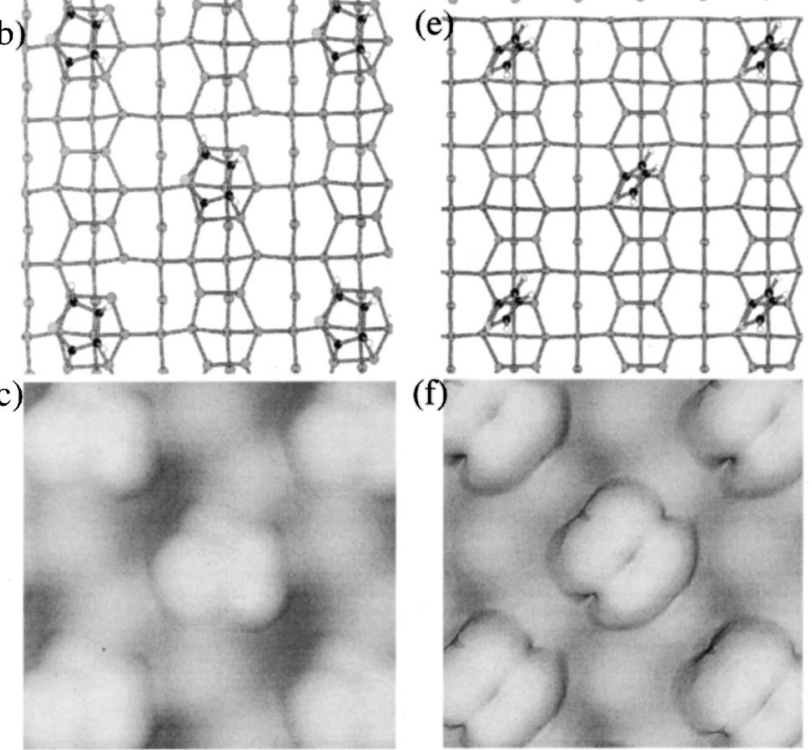

FIG. 12. The DFT optimized structure of the $\mathrm{SC}_{4} \mathrm{H}_{3}$ adsorption geometries with the lowest energy (a) and the second lowest energy (b). Other details are similar to Fig. 9.

culated constant current filled state STM images of aI and aII corresponding to a sample bias of $-2.5 \mathrm{~V}$ and a local density of states (LDOS) of $10^{-5} \AA^{-3}$. This value of the LDOS corresponds to a current around $10^{4} \mathrm{nA} .{ }^{52}$ Due to the limited numerical accuracy of the plane wave expansion of the electronic states in the vacuum region, this is the lowest LDOS (current) value we can use. We have found that the corrugation in the calculated STM image only depends weakly on the LDOS value, and we expect only minor changes in the STM image for the LDOS value corresponding to the experimental current of $1 \mathrm{nA}$ as used for recording the experimental image. Figure 10 shows the line profiles of the calculated images for both geometries aI and aII (Fig. 9) together with those for the experimental images of types A and B (Fig. 2) in two directions along the silicon dimer rows and in the perpendicular direction. Line profiles measured along a silicon dimer row and across dimer rows are used for aligning the profiles. The profiles of type B were taken by choosing a type B molecule locating on the left side of the silicon dimer row, while the line profiles along the dimer row were taken along the center of a dimer row. Hence an apparent height difference is visible between the two profiles taken along the dimer row [Fig. 10(a)] for types A and B. Besides, from the line profiles taken across the dimer rows it is also clearly seen that the type B molecule is located on the left side of the dimer. The peak at the position of $3.5 \AA$ in Fig. 10(b) reveals the corrugation of the dangling bond. ${ }^{52}$ Comparison of the molecular profiles reveals that the width and the height of the profiles in the calculated images are qualitatively consistent with those in the experimentally recorded images. This result 


\section{(a) Along the dimer row}

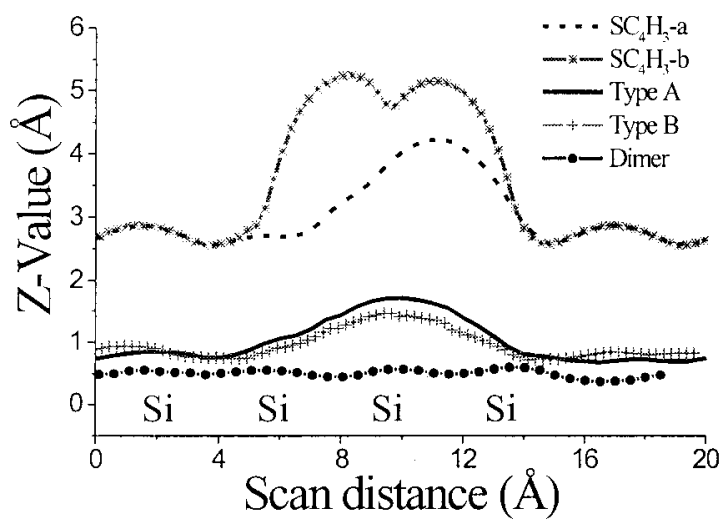

\section{(b) Perpendicular to dimer rows}

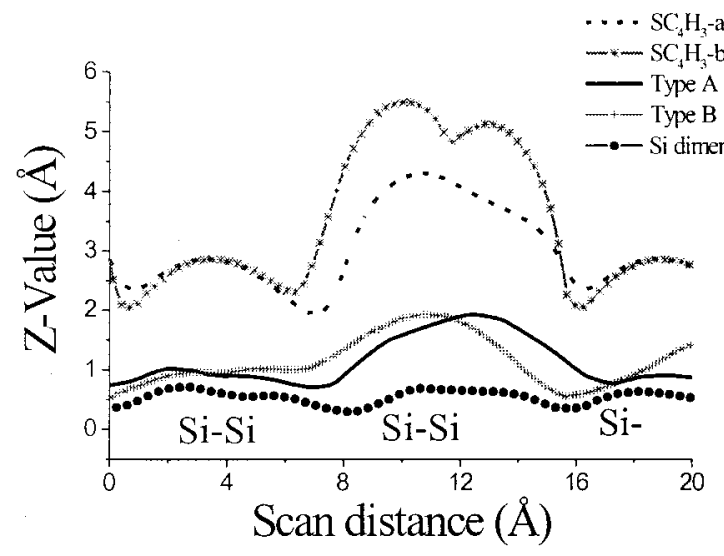

FIG. 13. Line profiles (upper) of the simulated STM image of $\mathrm{SC}_{4} \mathrm{H}_{3}$-a and -b geometries together with line profiles (lower) of the experimental STM image for type A and type B along (a) and perpendicular to (b) the Si dimer row. The line profiles measured along and across silicon dimer rows are also plotted as references.

further supports the fragmentation of 6T molecules into monomers upon adsorption on the clean $\mathrm{Si}$ surface. The line profile of the aI geometry appears symmetric with respect to the silicon dimer row, and we therefore link type A to the aI geometry. The line profile of geometry aII is very similar to the one of geometry aI, and it would be very hard to differentiate between these two geometries experimentally. However, since the adsorption energy of geometry aII is much higher than that of geometry aI, we do not expect geometry aII to be present on the surface.

Having shown how the four middle monomers $\left(\mathrm{SC}_{4} \mathrm{H}_{2}\right)$ interact with the $\mathrm{Si}$ atoms, the behavior of the terminal fragments $\mathrm{SC}_{4} \mathrm{H}_{3}$ with respect to the surface was investigated. To investigate the absorption of $\mathrm{SC}_{4} \mathrm{H}_{3}$ on the surface, we took as a starting point a selection of geometries that represented the local minima structures of category (a), (b) and (c) in Fig. 8. For each geometry we added one $\mathrm{H}$ atom to the $\mathrm{SC}_{4} \mathrm{H}_{2}$ molecule, and relaxed the coordinates. Figure 11 shows the four geometries, which have the lowest energy. To check the reliability of the AM1 results we used geometries (a) and (b) as starting points for the DFT calculations. The result is summarized in Table II. We see that there is a large difference between the AM1 results and the DFT results both in the absolute and relative energies. Thus it seems that in this case the AM1 results are not very reliable, which might be related to the fact that in this case the cluster has an odd number of electrons. The DFT(3) result in Table II is for a spinpolarized DFT calculation, and we see that spin polarization has a negligible effect on the DFT results. Since the AM1 results are not very reliable (relative energies have errors of 1 $\mathrm{eV}$ ), we can not trust that the AM1 geometries are a good starting point for the DFT calculations. Thus, to find the adsorption geometry of $\mathrm{SC}_{4} \mathrm{H}_{3}$ with the lowest energy we would probably need to make a full search within the DFT approximation which is not feasible.

Figure 12 shows the DFT optimized structure and corresponding theoretical STM images of the two AM1 geometries of $\mathrm{SC}_{4} \mathrm{H}_{3}$ which have the lowest energy. Note that within DFT it is geometry $\mathrm{SC}_{4} \mathrm{H}_{3}$-b that has the lowest energy while within $\mathrm{AM} 1$ it is $\mathrm{SC}_{4} \mathrm{H}_{3}$-a. We see that the $\mathrm{SC}_{4} \mathrm{H}_{3}$-b geometry gives rise to an asymmetric image, however, with a dip in the middle which is not seen in the experimental images. In Fig. 13 we plot the line profiles of the theoretical images of the $\mathrm{SC}_{4} \mathrm{H}_{3}-\mathrm{a}$ and -b geometries (Fig. 12) together with those of the STM images of types A and B (Fig. 2). The discrepancies in corrugation and shape between the theoretical and experimental images indicate that the two geometries do not correspond to the experimental images. This can have two reasons, either we have not found the global minimum because we used AM1 geometries as starting points, and this method is not very reliable in this case, or it is favorable to break off an additional $\mathrm{H}$ atom from $\mathrm{SC}_{4} \mathrm{H}_{3}$, and $\mathrm{SC}_{4} \mathrm{H}_{3}$ is therefore not observed on the surface. To investigate the latter we compare the adsorption energy of $\mathrm{SC}_{4} \mathrm{H}_{3}$ with the energy when $\mathrm{SC}_{4} \mathrm{H}_{2}$ and a single $\mathrm{H}$ atom are adsorbed on the surface. The adsorption energy of $\mathrm{H}$ is 3.19 $\mathrm{eV}$, while the energy cost of breaking a $\mathrm{H}$ atom from the $\mathrm{C}_{\alpha}$ atom of $\mathrm{SC}_{4} \mathrm{H}_{3}$ is $4.45 \mathrm{eV}$. Thus, from the adsorption energies in Tables I and II, we see that it is more favorable to keep the $\mathrm{H}$ atom attached to $\mathrm{SC}_{4} \mathrm{H}_{3}$. Hence, the asymmetric spots most likely correspond to $\mathrm{SC}_{4} \mathrm{H}_{3}$, but the geometry we have found in the theoretical calculation might not be the one with the lowest energy.

Thus the theoretical calculations support the experimental observation that upon adsorption on the silicon surface, 6T molecules dissociate into monomeric fragments by breaking the $\mathrm{C}_{\alpha}-\mathrm{C}_{\alpha}^{\prime}$ bonds. The STM images reveal two different configurations: symmetric and asymmetric with respect to the underlying $\mathrm{Si}$ dimer rows and we postulate that the symmetric one could link to the $\mathrm{SC}_{4} \mathrm{H}_{2}$ monomer and the asymmetric one to the $\mathrm{SC}_{4} \mathrm{H}_{3}$ monomer. Since the ratio of $\mathrm{SC}_{4} \mathrm{H}_{2}$ to $\mathrm{SC}_{4} \mathrm{H}_{3}$ is $4: 2$, we would expect double as many symmetric bright spots compared to the number of asymmetric bright spots in the images. However, since many of these bright spots are in clusters, it is difficult to obtain the exact ratio of these two different types by performing a statistical counting.

To understand the dissociation mechanism of 6T, we estimated the total energy involved in the dissociation from bond energies. Albeit we can not find the exact energy for cleaving the $\mathrm{C}_{\alpha}-\mathrm{C}_{\alpha}^{\prime}$ bonds, the mean dissociation energies of $\mathrm{C}-\mathrm{C}$ single $(3.61 \mathrm{eV})$ and double $(6.34 \mathrm{eV})$ bonds could set 

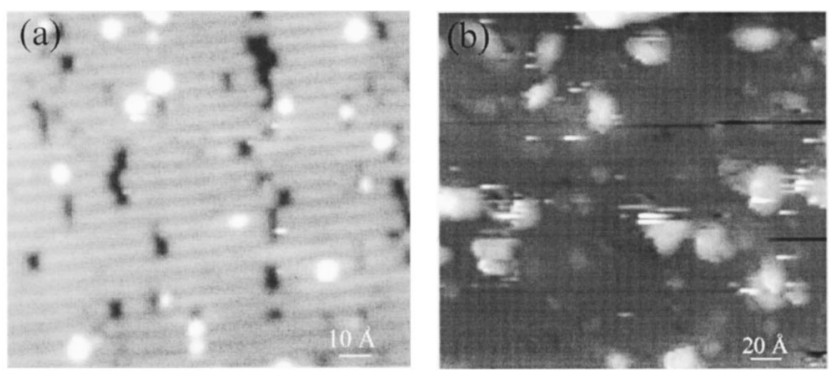

FIG. 14. (a) An STM image of the H-passivated $\mathrm{Si}(100)-(2 \times 1)$ surface with tunneling parameters of $\mathrm{I}_{\text {tunnel }}=0.2 \mathrm{nA}$ and $\mathrm{V}_{\text {sample }}=-2.5 \mathrm{~V}$. (b) An STM image of the H-passivated $\mathrm{Si}(100)-(2 \times 1)$ surface after exposure to $6 \mathrm{~T}$ molecules (deposition rate $=0.08 \AA / \mathrm{s}$, time $=30 \mathrm{~s}$ ).

the lower and upper limits of the $\mathrm{C}_{\alpha}-\mathrm{C}_{\alpha}^{\prime}$ bond energy, respectively. For each broken $\mathrm{C}-\mathrm{C}$ bond two $\mathrm{Si}-\mathrm{C}$ bonds are formed. The calculated $\mathrm{Si}-\mathrm{C}$ bond lengths are 1.897 and $1.925 \AA$, in accordance with the $1.89 \AA$ bond length of the $\mathrm{Si}-\mathrm{C}$ bond in organosilicon compounds. ${ }^{53}$ In organosilicon chemistry the typical bond energy for $\mathrm{Si}-\mathrm{C}$ is $3.30 \mathrm{eV}^{54}$ Thus by breaking $6 \mathrm{~T}$ into six monomers and forming ten new $\mathrm{Si}-\mathrm{C}$ bonds the system will gain an energy, which will fall into the interval between $10 \times 3.30 \mathrm{eV}-5 \times 6.34 \mathrm{eV}$ $=1.3 \mathrm{eV}$ and $10 \times 3.30 \mathrm{eV}-5 \times 3.61 \mathrm{eV}=14.95 \mathrm{eV}$. Hence, the dissociation of $6 \mathrm{~T}$ is energetically favorable.

In general, the same argument applies to all hydrocarbons having single or double $\mathrm{C}-\mathrm{C}$ bonds, i.e., upon adsorption it is energetically favorable to break single or double $\mathrm{C}-\mathrm{C}$ bonds and form two new $\mathrm{Si}-\mathrm{C}$ bonds for every broken $\mathrm{C}-\mathrm{C}$ bond. However, for most studied hydrocarbons-silicon systems the $\mathrm{C}-\mathrm{C}$ bond cleavage is not observed. For instance, unsaturated hydrocarbons, such as acetylene, ethylene or dienes, ${ }^{4}$ nondissociatively chemisorb on the $\mathrm{Si}(100)-(2 \times 1)$ surface while molecules having only single $\mathrm{C}-\mathrm{C}$ bonds, e.g., methane or propane,${ }^{13}$ do not adsorb at all. The reason for this lies on the fact the $\mathrm{C}-\mathrm{C}$ bond cleavage may be prohibited by a high kinetic barrier. In comparison, it seems that the kinetic barrier is much lower for the dissociation of 6T on the clean silicon surface. We speculate that this is due to the following; when the $\mathrm{C}_{\alpha}$ atoms react with the $\mathrm{Si}$ atoms, they will lose their $\pi$ bond character and instead become $s p^{3}$ hybridized. This can, for instance, be seen from the fact that the $\mathrm{C}_{1}-\mathrm{C}_{2}$ bond length of $1.52 \AA$, as listed in Table I, is close to the $\mathrm{C}-\mathrm{C}$ bond of $1.54 \AA$ in alkanes. ${ }^{53}$ Since $\mathrm{C}$ atoms in a $s p^{3}$ hybrid state will tetrahedrally bind to other $\mathrm{C}$ atoms, such a rehybridization would cause a gas phase $6 \mathrm{~T}$ molecule to twist from the planar conformation. However, when 6T is adsorbed on the surface, all monomeric rings are anchored to the $\mathrm{Si}$ atoms and the molecule cannot twist. Thus, the rehybridization will induce a large strain in the molecule that effectively lowers the kinetic barrier for the $\mathrm{C}_{\alpha}-\mathrm{C}_{\alpha}^{\prime}$ bond breakage.

\section{ADSORPTION OF 6T ON THE H-PASSIVATED SILICON SURFACE}

In Sec. III we have shown that $6 \mathrm{~T}$ molecules dissociate on the clean $\operatorname{Si}(100)-2 \times 1$ surface. After passivating the dangling bonds with these monomers, the surface becomes chemically inert and consequently the dissociation process slows down and longer oligomers start to appear on the surface. Therefore, we would expect that by terminating these highly reactive sites with atomic hydrogen, the adsorption behavior of 6T molecules on the H-passivated silicon surface will be different compared to the clean silicon surface. In addition, recently Lopinski et al. ${ }^{55}$ have demonstrated an approach for fabricating nanoscale organic structures on silicon surfaces, by employing minimal intervention by an STM tip and a spontaneous self-directed chemical growth process. Styrene molecule with $\mathrm{C}-\mathrm{C}$ double bonds could form straight molecular lines on the H-passivated silicon surface. This self-directed chain growth provides a relatively fast way of forming and/or connecting nanostructures on silicon surfaces, in comparison with constructing nanostructures via an STM tip. Their work also motivates us to further investigate the adsorption behavior of $6 \mathrm{~T}$ molecules on the $\mathrm{H}$-passivated $\operatorname{Si}(100)$ surfaces.

Figure 14(a) is an STM image of the H-passivated silicon surface before $6 \mathrm{~T}$ deposition. The reconstructed dimer row structure is still maintained after H-passivation. The bright spots on the surface are dangling bonds due to missing hydrogen atoms. After exposing this surface to $6 \mathrm{~T}$ molecules, the recorded images show bright and oval shaped features having about the same size, but fuzzy. Figure 14(b) shows an example of an STM image recorded for the H-passivated $\mathrm{Si}(100)$ surface after deposition of $6 \mathrm{~T}$ molecules. The average length of the features is found to be about $29 \AA$, close to the molecular length of $6 \mathrm{~T}$. Since these features were not observed before the 6T exposure, we believe that they are $6 \mathrm{~T}$ molecules which are weakly adsorbed on the H-passivated silicon surface. During scanning, it is observed that bright features may follow the tip movement until they bind to dangling bonds. We believe that the bright noisy spots represent $6 \mathrm{~T}$ molecules bound to dangling bonds at a single point around which it rotates randomly. Our measurements show no indication of chain reactions as in the case for styrene, ${ }^{55}$ or breakage of $6 \mathrm{~T}$ as for the clean silicon surface mentioned above. Based on our results, we propose that $6 \mathrm{~T}$ molecules probably interact with individual dangling bonds through the sulfur atoms. A similar mechanism was also proposed for thiophene adsorbed on $\mathrm{Si}(111)-(7 \times 7)$ at room temperature. ${ }^{56,57}$

\section{CONCLUSIONS}

We have investigated the adsorption mechanism of $\alpha$-sexithiophene on the clean and the H-passivated Si(100)- $(2 \times 1)$ surface by combining STM measurements with first principles electronic structure calculations. On the clean silicon surface the STM images reveal that at submonolayer coverage the molecules dissociate into monomeric fragments, which gives rise to two different STM spots, that are symmetric and asymmetric, with respect to the underlying silicon dimer rows. The dissociation arises from the strong interaction between the molecules and the dangling bonds. The theoretical calculations support the experimental results and link the STM images to the monomeric 
adsorption geometries. With increasing coverage of 6T, the dissociation process slows down, and in the end the complete molecules appear on the surface.

Whereas 6T molecules dissociate into monomers on the clean silicon surfaces, they stay intact on the H-passivated silicon surface and show high mobility due to the weak interaction with the substrate. The STM images also indicate that they can be anchored at the defect sites, e.g., sites missing atomic hydrogen.

\section{ACKNOWLEDGMENTS}

We thank Nicolai Stuhr-Hansen for sublimating the sample and Mikkel Bollinger for providing the routines for calculating Tersoff-Hamann STM images. This project was financed by the Danish Research Councils (STVF). F.B., K.S., and A.D.E. acknowledge partial support from E.C. TMP Project LAMINAT.

${ }^{1}$ J. T. Yates, Science 279, 5349 (1998).

${ }^{2}$ J. S. Hovis and R. J. Hamers, J. Phys. Chem. B 101, 9581 (1997).

${ }^{3}$ J. M. Buriak, Chem. Commun. (Cambridge) 1999, 1051.

${ }^{4}$ R. A. Wolkow, Annu. Rev. Phys. Chem. 50, 413 (1999).

${ }^{5}$ A. J. Mayne, A. R. Avery, J. Knall, T. S. Jones, G. A. D. Briggs, and W. H. Weinberg, Surf. Sci. 284, 247 (1993).

${ }^{6}$ H. Liu and R. J. Hamers, J. Am. Chem. Soc. 119, 7593 (1997).

${ }^{7}$ J. Yoshinobu, H. Tsuda, M. Onchi, and M. Nishijima, J. Chem. Phys. 87, 7332 (1987)

${ }^{8}$ C. C. Cheng, P. M. Wallace, P. A. Taylor, W. J. Choyke, and J. T. Yates, J. Appl. Phys. 67, 3693 (1990).

${ }^{9}$ L. Clemen, R. M. Wallace, P. A. Taylor, W. J. Choyke, W. H. Weinberg, and J. T. Yates, Surf. Sci. 268, 205 (1992).

${ }^{10}$ C. Huang, W. Widdra, and W. H. Weinberg, Surf. Sci. 268, 205 (1994).

${ }^{11}$ W. Pan, T. Zhu, and W. Yang, J. Chem. Phys. 107, 3981 (1997).

${ }^{12}$ U. Birkenheuer, U. Gutdeutsch, N. Rosch, A. Fink, S. Gokhale, D. Menzel, P. Trischberger, and W. Widdra, J. Chem. Phys. 108, 9868 (1998).

${ }^{13}$ M. J. Bozack, P. A. Taylor, W. J. Choyke, and J. T. Yates, Surf. Sci. 177, 933 (1986)

${ }^{14}$ M. Kiskinova and J. T. Yates, Surf. Sci. 325, 1 (1995).

${ }^{15}$ G. P. Lopinski, D. J. Moffatt, D. D. M. Wayner, and R. A. Wolkow, Nature (London) 392, 6679 (1998).

${ }^{16}$ R. J. Hamers, J. S. Hovis, S. Lee, H. B. Liu, and J. Shan, J. Phys. Chem. 101, 1489 (1997).

${ }^{17}$ F. Jolly, F. Bournel, F. Rochet, G. Dufour, F. Sirotti, and A. Taleb, Phys. Rev. B 60, 2930 (1999).

${ }^{18}$ R. Konecny and D. J. Doren, J. Am. Chem. Soc. 119, 11098 (1997).

${ }^{19}$ A. V. Teplyakov, M. J. Kong, and S. F. Bent, J. Am. Chem. Soc. 119, 11100 (1997).

${ }^{20}$ J. S. Hovis, H. Liu, and R. J. Hamers, Surf. Sci. 402, 1 (1997).

${ }^{21}$ Y. Taguchi, M. Fujisawa, T. Takaoka, T. Okada, and M. Nishijima, J. Chem. Phys. 95, 6870 (1991).

${ }^{22}$ R. A. Wolkow, G. P. Lopinski, and D. J. Moffatt, Surf. Sci. Lett. 416, L1107 (1998).

${ }^{23}$ S. Gokhale, P. Trischberger, D. Menzel, W. Widdra, H. Droge, H. P. Steinruck, U. Birkenheuer, U. Gutdeutsch, and N. Rosch, J. Chem. Phys. 108, 5554 (1998).
${ }^{24}$ W. A. Hofer, A. J. Fisher, G. P. Lopinski, and R. A. Wolkow, Phys. Rev. B 63, 085314 (2001).

${ }^{25}$ G. P. Lopinski, T. M. Fortier, D. J. Moffatt, and R. A. Wolkow, J. Vac. Sci. Technol. A 16, 1037 (1998).

${ }^{26}$ B. Borovsky, M. Kruger, and E. Ganz, J. Vac. Sci. Technol. B 17, 7 (1999).

${ }^{27}$ H. D. Jeong, Y. S. Lee, and S. Kim, J. Chem. Phys. 105, 5200 (1996).

${ }^{28}$ A. Dodalabapur, L. Torsi, and H. E. Katz, Science 268, 270 (1995).

${ }^{29}$ G. Horowitz, X. Z. Peng, D. Fichou, and G. Garnier, J. Appl. Phys. 67, 528 (1990).

${ }^{30}$ P. Ostoja, S. Guerri, S. Rossini, M. Servidori, C. Taliani, and R. Zamboni, Synth. Met. 54, 447 (1993).

${ }^{31}$ D. Fichou (ed.), in Handbook of Oligo- and Polythiophenes (Academic, New York, 1998), p. 271.

${ }^{32}$ F. Geiger, M. Stoldt, H. Schweizer, P. Bauerle, and E. Umbach, Adv. Mater. 5, 57 (1993).

${ }^{33}$ R. N. Marks, F. Biscarini, T. Virgili, M. Muccini, R. Zamboni, and C. Taliani, Philos. Trans. R. Soc. London, Ser. A 1725, 763 (1997).

${ }^{34}$ J. H. Schön, A. Dodalabapur, C. Kloc, and B. Batlogg, Science 290, 963 (2000).

${ }^{35}$ O. Bohme, C. Ziegler, and W. Gopel, Adv. Mater. 6, 587 (1994).

${ }^{36}$ M. Muccini, M. Murgia, F. Biscarini, and C. Taliani, Adv. Mater. 13, 355 (2001).

${ }^{37}$ F. Biscarini, R. Zamboni, P. Samori, P. Ostoja, and C. Taliani, Phys. Rev. B 52, 14868 (1995).

${ }^{38}$ F. Biscarini, P. Samori, O. Greco, and R. Zamboni, Phys. Rev. Lett. 78, 2389 (1997).

${ }^{39}$ P. Bauerle, T. Fischer, B. Bidlingmeier, A. Stabel, and J. P. Rabe, Angew. Chem. Int. Ed. Engl. 34, 303 (1995).

${ }^{40}$ M. B. Nardelli, D. Cvetko, V. De Renzi et al., Phys. Rev. B 53, 1095 (1996).

${ }^{41}$ A. Soukopp, G. Glockler, P. Kraft, S. Schmitt, M. Sokolowski, E. Umbach, E. Mena-Osteritz, P. Bauerle, and E. Hadicke, Phys. Rev. B 58, 13882 (1998).

${ }^{42}$ R. I. R. Blyth, F. Mittendorfer, J. Hafner, S. A. Sardar, R. Dushcek, F. P. Netzer, and M. G. Ramsey, J. Chem. Phys. 114, 935 (2001).

${ }^{43}$ E. R. Frank, X. X. Chen, and R. J. Hamers, Surf. Sci. 334, L709 (1995).

${ }^{44}$ J. J. P. Stewart, J. Comput. Chem. 10, 209 (1989).

${ }^{45}$ The Dacapo DFT code is publicly available at http://www.fysik.dtu.dk

${ }^{46}$ J. P. Perdew, J. A. Chevary, S. H. Vosko, K. A. Jackson, M. R. Pederson, D. J. Singh, and C. Fiolhais, Phys. Rev. B 46, 6671 (1992).

${ }^{47}$ D. Vanderbilt, Phys. Rev. B 41, 7892 (1990).

${ }^{48}$ H. J. Monkhorst and J. D. Pack, Phys. Rev. B 13, 5188 (1976).

${ }^{49}$ M. J. S. Dewar, E. G. Zoebisch, and E. F. Healy, J. Am. Chem. Soc. 107, 3902 (1985).

${ }^{50}$ M. J. Frisch, G. W. Trucks, H. B. Schlegel et al., GAussian 98, Revision A.7, Gaussian, Inc., Pittsburgh, PA, 1998.

${ }^{51}$ J. Tersoff and D. R. Hamann, Phys. Rev. B 31, 805 (1985).

${ }^{52}$ K. Stokbro, U. Quaade, and F. Grey, Appl. Phys. A: Mater. Sci. Process. 66, S907 (1998)

${ }^{53}$ A. Streitwieser, C. H. Heathcock, and E. M. Kosower, Introduction to Organic Chemistry, 4th ed. (Macmillan, New York, 1992).

${ }^{54}$ Y. Cao, K. S. Yong, Z. H. Wang, J. F. Deng, Y. H. Lai, and G. Q. Xu, J. Chem. Phys. 115, 3287 (2001).

${ }^{55}$ G. P. Lopinski, D. D. M. Wayner, and R. A. Wolkow, Nature (London) 406, 48 (2000).

${ }^{56}$ C. D. MacPherson, D. Q. Hu, and K. T. Leung, Surf. Sci. 276, 156 (1992).

${ }^{57}$ C. D. MacPherson and K. T. Leung, Phys. Rev. B 51, 17995 (1995). 